\title{
Characterization of genomic, physiological, and probiotic features of Lactiplantibacillus plantarum DY46 strain isolated from Turkish fermented turnip juice (Shalgam)
}

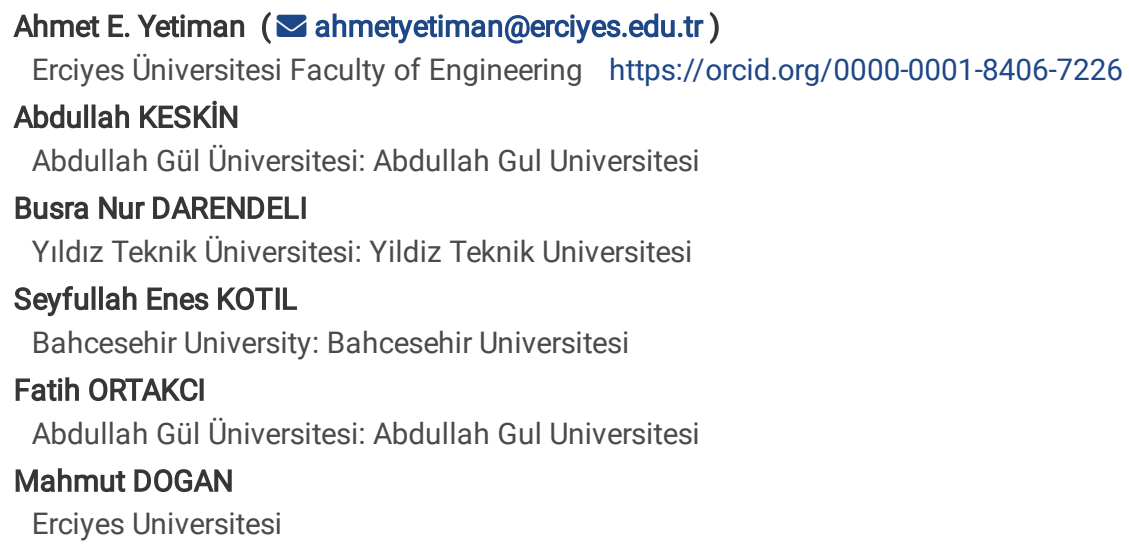

\section{Research Article}

Keywords: Shalgam, Lactiplantibacillus plantarum, probiotic, genome, carbohydrate fermentation patterns

Posted Date: August 30th, 2021

DOI: https://doi.org/10.21203/rs.3.rs-854638/v1

License: (c) (7) This work is licensed under a Creative Commons Attribution 4.0 International License. Read Full License

Version of Record: A version of this preprint was published at Food Bioscience on April 1st, 2022. See the published version at https://doi.org/10.1016/j.fbio.2021.101499. 


\section{Abstract}

A new $L$ b. plantarum strain DY46 was isolated from a traditionally fermented non-alcoholic beverage called shalgam from the Southern region of Anatolia following incubation on MRS agar at $30^{\circ} \mathrm{C}$ for 5 days. DY46 is gram-positive, short rod and catalase-negative. This bacterium fermented 22 of the 49 substrates tested on API CH50 fermentation panels. Whole-genome sequencing was performed using the Illumina Miseq platform to learn more about the metabolic capabilities of DY46. The sequences were assembled into a $3.32 \mathrm{Mb}$ draft genome using PATRIC 3.6.8. consisting of 153 contigs, and preliminary genome annotation was performed using the RAST algorithm. The DY46 genome consists of a single circular chromosome of 3,332,827 bp that is predicted to carry 3219 genes, including 61 tRNA genes, 2 rRNA operons. The genome has a GC content of $44.3 \%$ includes 98 predicted pseudogenes, 25 complete or partial transposases and 3 intact prophages. DY46 genome also predicted to carry genes of Plantaricin-E, Plantaricin-F and Plantaricin-K showing the antimicrobial potential of this bacterium which can be linked-to in vitro antagonism tests that DY46 can inhibit Salmonella Typimirium ATCC14028, Klebsiella pneumonie ATCC13883, and Proteus vulgaris ATCC8427. The acid and bile tolerance of DY46 revealed this strain could potentially pass through the stomach and reach into the gut to provide probiotic therapeutic affects on health.

\section{Introduction}

Lactic acid bacteria (LAB) by definition are gram (+), catalase $(-)$, anaerobic but aerotolerant fermentative. Lactic acid bacteria are utilized in the food biotech industry and possess well-documented beneficial effects on health (Buron-Moles et al. 2019; Evanovich et al. 2019). The LAB are considered as GRAS (Generally Recognized as Safe) by USDA and QPS (Qualified Presumption of Safety) by EFSA (Seddik et al. 2017). They usually act as bioprotective cultures owing to the biosynthesis of antimicrobials such as bacteriocin, nisin, enterocin, curvaticin, helveticin, plantaricin etc. (Gaggia et al. 2011; Tamang et al. 2016) which exist in many fermented dairy and vegetable products (Tamang et al. 2009; Jiang et al. 2012; Wouters et al. 2013; Mokoena 2017; Ribeiro et al. 2018). LAB play a crucial role in manufacturing fermented vegetables and can improve the nutritional value, flavor, food preservation of fermented foods (Liu et al. 2015).

The Shalgam is a highly popular beverage in the Turkey's west and southeast regions, where it is mostly produced and consumed (Tanguler and Erten 2012; Ekinci et al. 2016). Shalgam microbiota is reported to carry LAB thus show presumptive health benefits against several diseases and health risks (Ekinci et al. 2016; Seddik et al. 2017; Tanguler et al. 2021). Only a few studies attempted to uncover the microbial composition of the shalgam microbiome, for example, according to Agirman et al. (2021) shalgam is a rich source of Lactobacilli species where Lactocaseibacillus paracasei and Lactiplantibacillus plantarum are predominant strains in Shalgam microbial composition. Strains of $L b$. plantarum is well described for its probiotic functions because of its natural habitation in various environmental niches, such as all types of fermented foods, human and animal gastrointestinal tract (Zhang et al. 2012) and a number of its strains are heavily being utilized in commercial probiotic culture products. However, as of March 29, 2021, there are 215 genomes belonging to $L b$. plantarum strains deposited to NCBI and only three of these strains were isolated from fermented plant materials (i.e. pickled cabbage, pickles, Sichuan pickle)

(https://www.ncbi.nlm.nih.gov/genome/browse/\#!/prokaryotes/1108/). This limits the understanding of microbial community dynamics and microbial interactions in plant based fermented foods microbiome.

Although some research was performed on uncovering Shalgam microbiota, we didn't find any study evaluating the probiotic characteristics of LAB isolated from Shalgam. Our group isolated a novel Lactiplantibacillus plantarum strain DY46 from fermented Shalgam manufactured in the Southern region of Turkey and we investigated its phenotypic features used in screening and selection criteria of probiotics. The whole genome of the $L$ b. plantarum DY46 using Next Generation Sequencing and in silico metabolic potentials using bioinformatic tools are also explored. This is the first report describing phenotypic and genotypic characteristics in addition to in vitro probiotic potentials of a novel $L b$. plantarum DY 46 strain isolated from a plant-based traditional fermented beverage "Shalgam".

\section{Materials And Methods}

\section{Isolation of Bacterial Strain and Growth Conditions}

Lactiplantibacillus plantarum DY46 strain was isolated from a Turkish fermented turnip juice (shalgam) that was purchased from a local producer in Adana, Turkey. A $10 \mathrm{~mL}$ of the shalgam sample was diluted with $90 \mathrm{~mL}$ of Maximum Recovery Diluent (Merck, GmbH, Darmstadt, Germany) in a Schott bottle and homogenized for 1 minute with a highspeed vortex (IKA, Germany). Serial decimal dilutions were prepared from the same diluent and $100 \mu \mathrm{L}$ of each diluent was spread on MRS agar (Merck, $\mathrm{GmbH}$, Darmstadt, Germany). The plates were incubated at $30^{\circ} \mathrm{C}$ for $48 \mathrm{~h}$ in an anaerobic atmosphere. The DY46 isolate was selected from the dilution of $10^{-4}$ and subjected to colony purification twice. Then, gram staining and catalase tests were applied to the pure isolate of L. plantarum DY46, respectively. The cryo stocks of DY46 was prepared in MRS broth with $25 \%$ glycerol and were stored at $-80^{\circ} \mathrm{C}$.

\section{Genomic DNA extraction, identification, whole-genome sequencing and de novo assembly}

Prior to DNA extraction, Lactiplantibacillus plantarum DY46 cryo culture was sub-cultured twice in MRS broth followed by incubation anaerobically at $30^{\circ} \mathrm{C}$ for $24 \mathrm{~h}$. A $1 \mathrm{~mL}$ fresh culture was pipetted onto a sterile eppendorf tube and centrifuged at $6000 \mathrm{x} \mathrm{for} 10 \mathrm{~min}$ at $4^{\circ} \mathrm{C}$. Total DNA extraction 
from pellet was carried out using the PureLink Genomic DNA Mini Kit (Invitrogen, Thermo-Fisher Scientific, USA) per manufacturer's instructions for gram-positive bacteria. The quality and concentration of genomic DNA were checked by a Qubit 3.0 fluorometer (Thermo-Fisher Scientific, US) and agarose gel (1.5\%). Identification of the test strain was carried out by full-length nucleotide sequencing of the 16S rDNA gene. Universal bacterial primers 27F (5'-AGAGTTTGATCCTGGCTCAG-3') and 1492R (5'-GGTTACCTTGTTACGACTT-3') were employed (Ni et al. 2015). Amplification reactions were prepared with a total volume of $30 \mu \mathrm{L}$ containing, 3 units of EasyTaq DNA polymerase (TransGen Biotech, Beijing, China), $3 \mu \mathrm{L}$ of $10 \mathrm{x}$ EasyTaq Buffer, $20 \mu \mathrm{M}$ of forward primer, $20 \mu \mathrm{M}$ reverse primer, $0.9 \mu \mathrm{L}$ DMSO (3\%), $2.4 \mu \mathrm{L} 2.5 \mathrm{mM}$ dNTP, $22.1 \mu \mathrm{L}$ nuclease-free water and 50ng template DNA. Reaction mixes were amplified with a thermal cycler (ABI Veriti 96, Thermo-Fisher Scientific, California, USA) under the following conditions: the initial denaturation of DNA for 5 minutes at $94^{\circ} \mathrm{C}$ was followed by 30 cycles of denaturation at $94^{\circ} \mathrm{C}$ for $30 \mathrm{~s}$, annealing at $52^{\circ} \mathrm{C}$ for $20 \mathrm{~s}$, extension at $72^{\circ} \mathrm{C}$ for $90 \mathrm{~s}$, and followed by a $5 \mathrm{~min}$ final extension at $72^{\circ} \mathrm{C}$. The PCR products were run on agarose gel $(1.5 \%)$ and sequenced by the Sanger method (Ficus Biotechnology, Ankara, Turkey). The obtained sequences were searched against the Basic Local Alignment Search Tool (NCBI-BLAST). After confirming the DY46 strain via 16S rDNA, the whole genome sequencing libraries were constructed using Nextera XT DNA Library Preparation Kit and sequencing was fulfilled by Illumina Miseq platform as paired-end (PE) $2 \times 250$ bases read. The low-quality reads were filtered and assembled in the genome assembly service of PATRIC 3.6.8. (https://patricbrc.org/app/Assembly2) with an auto strategy (Davis et al. 2020).

\section{Bioinformatic analyses}

Genome annotation and comprehensive genome analysis were performed by using NCBI Prokaryotic Genome Annotation Pipeline (PGAP) and PATRIC 3.6.8. platform (Tatusova et al. 2016; Davis et al. 2020). A circular genome map of the strain genome was generated with CG view server (Stothard and Wishart 2005). The calculation of orthologous average nucleotide identity values (OrthoANI) of the DY46 and other compared L.plantarum, L.pentosus and L. paraplantarum strains were implemented by OrthoANI tool v0.93.1 (Lee et al. 2016). Prediction of metabolic pathways of L. plantarum DY46 was carried out using BlastKOALA for scanning against the KEGG database (Kanehisa et al. 2016). The bacteriocin production responsible gene cluster prediction was fulfilled using the BAGEL 4 webserver (http://bagel4.molgenrug.nl/) (Heel et al. 2013). Following, each member of predicted gene clusters was confirmed via the NCBI protein BLAST suite (https://blast.ncbi.nlm.nih.gov/Blast.cgi). Theoretical isoelectric point $(\mathrm{pl})$ and molecular mass $(\mathrm{MW})$ of the predicted peptides were calculated by Expasy Compute pl/MW online tool (https://www.expasy.org/resources/compute-pl-mw). The prophage regions on the genome of DY46 were identified and annotated with the PHASTER-Phage Search Tool Enhanced Release (Arndt et al. 2016). In order to identify the genes transferred horizontally, all protein-coding genes obtained from PHASTER were screened against the non-redundant protein (NR) database by performing protein-BLAST. If a gene's homologous protein was found to match a microorganism other than L. plantarum $\geq 80 \%$, that gene was considered horizontally transferred (Liu et al. 2015 ). A resistome screening was executed by scanning the complete genome sequences of the DY46 strain versus the ResFinder 4.1, CARD, PATRIC 3.6.8 and KEGG databases, respectively (Kanehisa et al. 2016; Alcock et al. 2020; Bortolaia et al. 2020; Davis et al. 2020). As with the phage elements, horizontal gene transfer screening was performed within the detected resistome. The complete genome sequences of the DY46 have been submitted to NCBI under accession number JAFFQQ000000000.

\section{Carbohydrate fermentation}

The carbohydrate fermentation patterns of the DY46 strain were determined using an API 50 CHL kit (BioMérieux, Marcy l'Etoile, France) consisting of 49 different carbohydrate tests in accordance with the manufacturer's protocols.

\section{Determination of antibiotic susceptibility}

Antibiogram assays were conducted to find out the resistance or sensitivity of the DY46 strain against commonly used antibiotics. Ready to use commercial antibiotic disks (methicillin, vancomycin, amikacin, kanamycin, azithromycin, tetracycline, penicillin G (Bioanalyse); ampicillin, oxacillin, carbenicillin, amoxycillin, streptomycin, erytromycin, rifampacin (oxoid)) were employed for antibiotic susceptibility testing of L. plantarum DY46. The application of disk diffusion assay was performed according to a modified Kirby-Bauer method (Sharma et al. 2017). Interpretation of inhibition zone $(\mathrm{mm})$ results was carried out with regard to Clinical and Laboratory Standards Institute's performance standards for antimicrobial testing (CLSI M100-S22, 2012). Results with an inhibition zone less than or equal to $14 \mathrm{~mm}$ were noted resistant (R). Additionally, inhibition zones greater than 20 $\mathrm{mm}$ were considered sensitive (S) and between 15-19 mm were accepted as semi-sensitive or intermediate (I).

\section{Probiotic Properties}

To determine probiotic properties of the DY46: $\beta$-haemolysis, cell surface hydrophobicity, cellular auto-aggregation, GABA-production capacity tests and antibacterial activity assay against several pathogens were performed, respectively. On the other hand, the growth kinetics of the DY 46 were analyzed at different $\mathrm{pH}$ and bile concentrations. Evaluation of the $\beta$-haemolytic activity of the DY46 was performed using $5 \%$ sheep blood containing Columbia agar plate. The isolate was streaked on the Columbia agar followed by incubation at $37^{\circ} \mathrm{C}$ for $48 \mathrm{~h}$ under anaerobic conditions (Angmo et al. 2016). Cell surface hydrophobicity and auto-aggregation assays were performed in compliance with Goel et al. (2020). Antibacterial activity assay was executed by the agar well diffusion method (Mishra and Prasad 2005). The supernatant of 18-20 h grown DY46 was analyzed against E. coli 0157:h7 (ATCC 43895), S. aureus (ATCC 25923), B. Cereus (ATCC 33019), S. Typhimurium (ATCC 14028), P. mirabilis (ATCC 29906), P. vulgaris (ATCC 8427) and K.pneumoniae (ATCC 13883). Growth characteristics of the DY46 were investigated at different pH and bile concentrations. First, the overnight grown fresh culture of DY46 was prepared in MRS broth at $30^{\circ} \mathrm{C}$. Second, the MRS medium was prepared to 
create media with different conditions. Third, Oxyrase (Sigma-Aldrich, USA) was added to the prepared media to reduce the oxygen level. The pH of the MRS medium was adjusted to a value between 6.8-8.4 which is optimum for oxyrase. After adjusting the pH value, oxyrase was added to the medium in proportions according to McMahon et al. (2020). MRS medium with five different pH values ( $\mathrm{pH} 2,3,4,5,7)$ was prepared using $3 \mathrm{~N} \mathrm{HCl}$ and $3 \mathrm{~N} \mathrm{NaOH}$. For the preparation of bile concentrations of a different pre-separated MRS medium, the pH was adjusted to 6.5. Four different bile concentrations $(0.3 \%, 0.5 \%, 1 \%$ and control (no bile)) were prepared using ox bile extract (Sigma, Germany). After preparing all media, they were incubated at $36.5^{\circ} \mathrm{C}$ for 30 minutes to activate oxyrase. Growth measurements were performed in HIDEX Sense Microplate Reader (Hidex, Finland) using 96 well-plates with lid. Each well was inoculated with $200 \mu \mathrm{l}$ from media containing the previously indicated ratios (McMahon et al. 2020). Samples were inoculated in quadruplicate. Spectrophotometric measurements were carried out at $30^{\circ} \mathrm{C}$ and $37^{\circ} \mathrm{C}$ with a $300 \mathrm{rpm}$ orbital shake. An optical density (OD) measurement at a wavelength of $600 \mathrm{~nm}$ was performed every 20 minutes at 72 hours post-inoculation.

\section{Results And Discussion The Genome of the DY46 strain}

The whole genome of the L. plantarum DY46 strain composed of a circular chromosome of 3,332,827 bp with a GC ratio of $44.3395 \%$, a total of 3.219 genes, comprising of 3.054 protein-coding sequences, 61 tRNAs, 2 rRNAs, 4 non-coding RNAs and 98 pseudogenes (Fig. 1. and Table 1. ). As a result of the KEGG orthology screening, the encoded proteins identified on the genome of the DY46 strain were classified in 20 different functional categories and summarized in Table S22. The Ortho ANI values of the DY46 and other Lb. plantarum strains were displayed in Fig. 2. Based on Ortho ANI results, $L b$. plantarum DY46 showed a high level of identical genetic reciprocal similarity of $99.36 \%, 99.05 \%, 99.03 \%, 99.02 \%$ for $L b$. plantarum ATCC 8014, WCFS1, ATCC 14917 and ST-III respectively. ATCC 8014 and 14917 were isolated from pickled cabbage, while the well-known probiotic strain WCFS1 was isolated from human saliva (Kleerebezem et al. 2003; Siezen et al. 2010). The strains of ATCC 8014 , WCFS1 and ATCC 14917 are commercial strains and considered probiotics (Gaudana et al. 2010; Liu et al. 2015). The ST-III strain was originated from a Korean fermented vegetable called "kimchi"(Wang et al. 2011). On the other side, the strains RI-113 (98.99\%), Y44(98.97\%) and LL441(98.7\%) showed the lowest genetic similarity to the DY46 among the studied L. plantarum strains. As expected, LL441 (cheese) and RI-113 (salami) showed a greater genetic distance than other strains due to their isolation sources (Gonzalez et al. 1994; Flórez and Mayo 2018; Inglin and Meile 2020). L. plantarum can be found in many different environments and shares its ecological niche with $L$. pentosus and $L$. paraplantarum and other facultative heterofermentative members of the genus Lactobacillus (Stiles and Holzapfel 1997). Besides, L. plantarum, L. pentosus and L. paraplantarum display very close phenotypes and are genotypically similar due to their rRNA have as same as sequence identity (>99\%). Therefore, these species cannot be discriminated from each other using 16s rDNA sequence analysis (Parente et al. 2010). According to Ortho ANI results which were shown in Fig. 2. L. paraplantarum and L. pentosus exhibit $85.89 \%$ and $79.93 \%$ similarity with the DY46 strain, respectively. It is usually reported that the ANI value should be above $95-96 \%$ to consider that the genomes of the two species are the same (Lee et al. 2016). This confirms that the DY46 strain belongs to the $L b$. plantarum species.

Table 1 Genomic features of Lactiplantibacillus plantarum DY46

\begin{tabular}{|ll|}
\hline Item & Complete Genome \\
\hline Size (bp) & 3.332 .827 \\
GC content (\%) & 44.3395 \\
\hline Genes (total) & 3.219 \\
\hline Protein coding sequences & 3.054 \\
\hline tRNA & 61 \\
\hline rRNA & 2 \\
\hline Non-coding RNA & 4 \\
\hline Pseudogenes & 98 \\
\hline
\end{tabular}

\section{Carbohydrate Fermentation}

The lactobacilli can derive ATP from heterofermentative and/or heterofermentative carbohydrate fermentation based on each species/strain preference of sugar utilization. Uncovering carbohydrate fermentation patterns has been widely applied to determine phenotypic traits. Per API 50 $\mathrm{CHL}$ test results DY46 can metabolize 22 different carbohydrates out of 49 being tested (Table S21). It is important to note that DY46 cannot metabolize D-Sorbitol, although its genome has sorbitol-6-phosphate 2-dehydrogenase (srID) and the glucitol/sorbitol phosphotransferase system ( $s r l B, s r l E$ and $s r l A$ ) genes. This might be due to the lack of expression of the abovementioned genes encoding specific enzymes required to metabolize sorbitol (Buron-Moles et al. 2019). Lactiplantibacillus plantarum is a protean and resilient species that can grow on a wide range of 
carbohydrate sources. This phenotypic character is associated with genes involved in carbohydrate metabolism and transport. Most of the transporters involved in carbohydrate metabolism are located in the phosphoenolpyruvate-dependent sugar phosphotransferase system (PTS) (Gänzle and Follador 2012; Gao et al. 2020). The entire PTS of DY46 strain that was encoded by its genome, comprises PTS System Enzyme I (general enzyme gene, $p t s)$, phosphocarrier protein HPr gene (ptsh), 26 complete/incomplete substrate-specific enzyme II (EII) complexes genes (Table S24). In the genome of the DY46 strain, the genes of glucose-glucoside, fructose-mannose-sorbose, glucitol, Lactose-N, N'-diacetylchitobioseB-glucosides and N-Acetylglucoseamine Ell complex families were observed as multiple copies, while L-ascorbate, sorbose, mannitol and galactitol Ell complex genes were found as single copies. Additionally, the DY46 possesses several other carbohydrate transporter encoding genes on its genome. However, their substrate specificity is unknown and could not be predicted. According to Kleerebezem et al. (2003) various sugar transporter systems are known to import more than one substrate. Lb. plantarum is classified into the facultative heterofermentative Lactobacillus species, which utilize the sugars by way of glycolysis (Embden-Meyerhof-Parnas (EMP) pathway) or the phosphoketolase (PK) pathway, leading to homolactic or heterolactic fermentation routes, respectively (Liu et al. 2015). DY46 genome carries 6-phosphofructokinase 1, fructose-bisphosphate aldolase, glucose-6-phosphate isomerase, transketolase and phosphoketolase genes, which are encoding the key enzymes of EMP and PK pathways (Eiteman and Ramalingam 2015). The genes encoding enzymes related in the intact EMP and PK pathways were predicted in the genome of the DY46 strain and listed in Table S23. Furthermore, 1-phosphofructokinase enzyme encoding fruK gene was detected which is used as the key gene for differentiation of hetero- and homofermentative lactobacilli species (Orita et al. 2008; Zheng et al. 2015). On the other hand, Buron-Moles et al. (2019) reported that obligate heterofermentative strains lacked the 1-phosphofructokinase (PFK) enzyme, in addition to PFK absence, both obligately and facultative heterofermentative species were specifically characterized by the presence of L-arabinose isomerase, L-ribulose kinase and ribulose phosphate epimerase enzymes, respectively (Buron-Moles et al. 2019). Although these enzymes are not found in the genome of DY46, it could be predicted that DY46 has a facultative heterofermentative carbohydrate metabolism like other $\mathrm{Lb}$. plantarum strains.

DY46 also possesses six L-Lactate dehydrogenase (IdhL) genes in the genome of DY46 which is smaller than what Liu et al. (2015) and Gao et al. (2020) reported. The DY 46 appears to be capable of synthesizing only a single isomer of lactate, which may be due to a stable chromosomal deletion (Ferain et al. 1994). Apart from the lactate dehydrogenase genes, the DY46 genome has several other pyruvate depletive enzymes which are responsible for the synthesis of other flavor compounds, such as acetaldehyde, acetoin, oxaloacetate, acetoin and ethanol (Papagianni 2012; Gao et al. 2020). Moreover, the D-lactose and D-galactose fermenting capacity of the DY46 confirmed by both in vitro and in silico analysis. The API results revealed that DY 46 was able to utilize glucose and lactose while, the BlastKOALA scanning results revealed that all enzymes of the Leloir metabolic pathway were present, together with 2 copies of the beta-galactosidase gene in the genome of the DY46.

The Leloir pathway enzyme encoding genes in the DY46 genome consist of one copy of galactokinase gene, one copy of UDP-glucose-hexose-1phosphate-uridylyltransferase gene, four copies of UDP-glucose-4-epimerase and three copies of aldose-1-epimerase genes. The presence of genes encoding major enzymes of galactose metabolism and in vitro test results are hallmarks of the potential utilization of the DY46 as a dairy starter culture. Similar to Lb. plantarum strains of WCFS1(Kleerebezem et al. 2003), 5 - 2(Liu et al. 2015), Y44 (Gao et al. 2020 ) and ZJ316 (Li et al. 2016), the $L$ b. plantarum DY46 genome did not encode all of the tricarboxylic acid cycle-related proteins, although certain genes were found and shown in Table S23. According to KEGG mapper results, the genome of the DY46 strain encloses 203 genes that are related to central and other carbohydrate metabolism. The composition of those gene pools are as follows: 23 glycolysis/gluconeogenesis related genes, 8 TCA cycle-associated genes, 15 pentose phosphate pathway genes, 4 pentose and glucuronate interconversions related genes, 19 fructose and mannose metabolism genes, 19 galactose metabolism genes, 3 ascorbate and aldarate metabolism genes, 22 starch and sucrose metabolism genes, 27 amino sugar and nucleotide sugar metabolism genes, 28 pyruvate metabolism genes, 11 glyoxylate and dicarboxylate metabolism genes, 11 propanoate metabolism genes, 8 Butanoate metabolism genes, 3 C5-branched dibasic acid metabolism genes, 3 inositol phosphate metabolism genes. The gene number associated with carbohydrate metabolism is the same as $L$ b. plantarum Y44 (Gao et al. 2020). The number of carbohydrate-active enzyme genes of Lb. plantarum ZLP001 (Zhang et al. 2018) and Lb. plantarum KDLS1.0391 (Jia et al. 2017) were reported relatively low (119 and 190 genes, respectively) than the DY46 strain. However, there was no evidence of carbohydrate fermentation patterns that were found to be able to compare with the DY46 strain. In addition, as shown in table 3, Y44 (24 sugars) and ATCC14917 (25 sugars) were able to metabolize a higher number of sugars than DY46. These differences may arise from the physiological and genetic adaptation of the strains to the ecological niches in which they were being isolated.

\section{Bacteriocin biosynthesis}

According to the results of the whole genome search of the DY46 strain against the BAGEL database, the gene cluster responsible for bacteriocin biosynthesis consists of 26 genes and its total length is approximately $24.2 \mathrm{~kb}$ (Fig. 3). In this gene cluster, transport-related genes, immunity protein and plantaricin precursor genes and several core genes ( $P / n E, P I n F$ and $p / n K$ ) are encoded and all protein sequences confirmed by protein BLAST (Table S1). L. plantarum DY46 strain was found to have the same core genes encoding Class II bacteriocins as ATCC8014 (Yu et al. 2020$)$. The pInEF locus is widely distributed among L. plantarum strains isolated from various ecological niches. The well-studied $p / n E F$ loci have also been reported in L. plantarum WCFS1, NC8, JDM1, C11, V90, J51 and J23 strains, respectively (Tai et al. 2015). On the other hand, the isoelectric points (pl) and amino acid lengths of the pln E and pln F mature peptides that do not have the GG leader sequence that we detected (Table S2) are identical to pln E and pln F bacteriocins that were previously reported in WCFS1, NC8, J23, J51, C11 and V90 strains (Diep et al. 2009). Normally, plnJ and pln $\mathrm{K}$ peptides, which are subunits of plantaricin JK, are encoded in the same gene cluster/operon and more effective together, whereas in the present study only the pln K peptide was detected with $95.35 \%$ percent identity (Todorov 2009). Moreover, the pl (8.59) and length of the mature pln K

Page 5/14 
peptide (28aa) detected have differed significantly from the mature plnK peptides (pl:10.52; 32aa) as previously reported in C11, NC8, V90 and WCFS1 (Diep et al. 2009). Apart from the core genes, the presence of secretion genes pln H (HlyD, accessory protein for ABC-transporter; (Accession no: WP_027821501.1), pln G (LanT, Bacteriocin ABC-transporter; WP_027821502.1) have been verified in the plantaricin gene cluster. Bacteriocin $A B C$ transporters are involved in the transport of the mature peptide through the cell membrane, which is formed by deleting the leader peptide sequence from prebacteriocin (Havarstein et al. 1995). The accessory protein (also called the accessory factor) is another necessary component for the $A B C$ transporter system-dependent translocation process (Nes et al. 1996). Another gene cluster member identified is the putative $\mathrm{Na}^{+} / \mathrm{H}^{+}$ antiporter protein (orf00033: AFM80194.1), which sustainably maintains intracellular proton balance and leading to the enabling of ATP required for ABC transporters (Jia et al. 2017). In addition, the bacteriocin gene cluster contains genes encoding orf00020 (CAAX amino terminal protease family protein; EFK30757.1) and orf 00028 (bacteriocin immunity protein; WP_127526380.1) immunity proteins that play a role in protecting bacteria from their mature bacteriocins (Todorov 2009). The other members of the bacteriocin biosynthetic gene cluster were listed in supplemental table S1.

\section{Antibiotic resistance}

Antibiotic susceptibility of the DY46 strain was evaluated as reported by the Clinical and Laboratory Standards Institute's performance standards. The zone of inhibition (ZOI) values of fourteen antibiotics tested against the DY46 strain was shown in Table S3 with resistome search match results. DY46 was found to be resistant $(\mathrm{ZOI} \leq 14 \mathrm{~mm})$ to methicillin $(5 \mu \mathrm{g})$, oxacillin $(1 \mu \mathrm{g})$, streptomycin $(10 \mu \mathrm{g})$, vancomycin $(30 \mu \mathrm{g})$, amikacin $(30$ $\mu \mathrm{g})$, kanamycin $(30 \mu \mathrm{g})$, azithromycin $(15 \mu \mathrm{g})$, tetracycline $(30 \mu \mathrm{g})$ and rifampacin $(5 \mu \mathrm{g})$. Apart from these, DY46 was sensitive (ZOI $\geq 20 \mathrm{~mm})$ to ampicillin $(10 \mu \mathrm{g})$, carbenicillin $(100 \mu \mathrm{g})$ and amoxycillin $(25 \mu \mathrm{g})$, while it showed intermediate sensitivity (ZOI 15 to 19 mm) to Penicillin G (10 U) and Erythromycin $(10 \mu \mathrm{g})$. The antibiotic resistance profile of the DY46 strain showed partial similarity with the previously reported $L$. plantarum profiles (Sharma et al. 2016, 2017; Klarin et al. 2019). There are no antibiotic resistance genes that have been found in both the ResFinder 4.1 and CARD databases. However, twenty-one antibiotic resistance genes which were shown in Table S3 have been detected with PATRIC 3.6.8 and KEGG databases. The identified genes were found to be related to $\beta$-Lactams (9), Streptomycin (2), Vancomycin (7), Macrolides (1), Tetracyclines (1) and Rifampacin (1). It is commonly accepted that Lactobacillus species have very high resistance to aminoglycosides. $L b$. plantarum is known to be resistant to vancomycin due to its intrinsic peptidoglycan precursors consisting of D-lactate instead of D-alanine at the C-terminus (Gueimonde et al. 2013; Álvarez-Cisneros and Ponce-Alquicira 2018; Campedelli et al. 2019). Besides, the VanX gene is highly specific for hydrolyzing D-ala-D-ala dipeptides and a significant precursor of the cell wall (Liu et al. 2015). The vancomycin resistance genes were identified in the genome of DY46 consists of phospho-N-acetylmuramoyl-pentapeptide-transferase (mraY), alanine racemase (alr), D-alanyl-D-alanine ligase ( $d d l)$, UDP-Nacetylmuramoyl-tripeptide-D-alanyl-D-alanine ligase ( $m u r F$ ), UDP-N-acetylglucosamine-N-acetylmuramyl-(pentapeptide) pyrophosphorylundecaprenol N-acetylglucosamine transferase (murG), D-Ala-D-Ala carboxypeptidase (van Y) and D-Ala-D-Ala dipeptidase (vanX). In addition, streptomycin resistance responsible gibD and $S 12 p$ genes were detected. However, no specific genes were found for amikacin and kanamycin, even if resistance was present. This is because genotype and phenotype do not overlap completely (Zhang et al. 2012). Apart from these, $R / m A$ (II) (23S rRNA (guanine(748)-N(1))-methyltransferase), S10p (SSU ribosomal protein S10p (S20e)), rpoB (DNA-directed RNA polymerase beta subunit) genes detected which were related with macrolides, tetrcyclines and rifamycins, respectively. Moreover, mecA (penicillin-binding protein $1 A$ ), $p b p 2 a$ (penicillin-binding protein $2 \mathrm{~A}$ ) and PenP (beta-lactamase class A) major genes responsible for beta-lactam resistance were detected on the DY46 genome. Methicillin and oxacillin resistance is known to be associated with penicillin-binding proteins. Interestingly, resistance to Penicillin $\mathrm{G}$ was observed in DY46, although Lactobacillus are known to be susceptible. Some authors have reported Penicillin G-resistance in recent years in some strains of Lactobacillus rhamnosus, Lactobacillus reuteri, and Lactobacillus plantarum, which also confirms our study (Abriouel et al. 2015; Zheng et al. 2017). Because of the growing concern that foods and/or common bacteria may serve as potential reservoirs for antimicrobial resistance genes, probiotics must not carry transferable antimicrobial resistance genes to be used for humans or animals (Zhang et al. 2012). Because many Lactobacillus species have intrinsic resistance to many antimicrobial compounds, and such resistance is known not to be associated with any particular safety concerns. However, the intrinsic antibiotic resistance genes on the chromosome should not be flanked by integrases and/or transposases. As a result of Protein BLAST screening for antibiotic resistance genes detected in this study, no evidence of horizontal gene transfer was found (Table S20).

\section{Prophages and horizontal gene transfer}

Prophage search results display 9 prophage regions (three intact, two questionable and four incomplete) found in the genome of the DY46 strain and summarized in Table 2. One of the three intact prophage regions showed similarity with Lactob_Sha1_NC_019489 (48.8Kb), (region 1), and the other two like Lactob_phig1e_NC_004305 (39.9Kb) and Staphy_SPbeta_like_NC_029119 (29.6Kb), region 2 and region9, respectively (Fig S1.). It was determined that Lactob_Sha_1 and Lactob_phig1e showed the highest protein matching among the identified prophages. These are the most common temperate prophages ever described in L. plantarum strains (Pei et al. 2020). All the prophage regions have attL/attR sequences and integrase except for region 6 (Paenib_PBL1c) and 7 (Bacill_vB_BtS_BMBtp14). In bacterial genomes, integrases are functional identifiers for phages, pathogenicity islands and integrative plasmids (Juhas et al. 2009; Liu et al. 2015). Three integrases (PP_00611(region 1), PP_01193(region 2) and PP_03267 (region 9)) were determined in the identified intact regions. The location of attL/attR sequences varies within intact phages. The attL sequences in regions 2 and 9 are located upstream of the integrase, while the attR sequence of region 1 was found downstream of the integrase. Additionally, attL and attR sequences of phage 1 and phage 9 were identical, but the attL and attR sequences of phage 2 are different from them. The Intact phage region 1 extends from 558,178 bp to 607,042 bp of the genome and includes 58 protein-coding sequences containing all prophage components from PP_00554 (transposase) to PP_00611 (phage integrase). The intact region 2 extends from 1,217,186 bp to 1,257,125 bp of the 
genome and consists of 49 protein-coding sequences containing prophage components from PP_01193 (phage integrase) to PP_01241. Moreover, the intact region 3 (9) is located between 3,302,034 bp to 3,331,708 bp of the genome and consists of 33 protein-coding sequences containing prophage components from PP_03263 (protease) to PP_03295. Unlike previously reported for L. plantarum WCFS1(Ventura et al. 2003) and 5 - 2 strains (Liu et al. 2015), only the two intact phages (Sha1 and phig1e) were found to contain all packaging/head/tail gene clusters, DNA packaging genes and the lysis cassette. All components of the identified prophage elements have been listed in Table S4-S12.

Table 2

The predicted prophage regions of Lactiplantibacillus plantarum DY46 genome

\begin{tabular}{|c|c|c|c|c|c|c|c|c|c|}
\hline Region & Length & Completeness & Score & $\begin{array}{l}\text { Region } \\
\text { Position } \\
\text { (bp) }\end{array}$ & $\begin{array}{l}\text { Total } \\
\text { Proteins }\end{array}$ & $\begin{array}{l}\text { Most Common Phage } \\
\text { (Number of matching proteins) }\end{array}$ & GC\% & $\begin{array}{l}\text { attL/attR } \\
\text { sites }\end{array}$ & $\begin{array}{l}\text { Integrase } \\
\text { ORF start- } \\
\text { stop }\end{array}$ \\
\hline 1 & $48.8 \mathrm{~Kb}$ & Intact & 150 & $\begin{array}{l}558178- \\
607042\end{array}$ & 58 & Lactob_Sha1_NC_019489 (27) & 41.1 & + & $\begin{array}{l}605879- \\
607042\end{array}$ \\
\hline 2 & $39.9 \mathrm{~Kb}$ & Intact & 150 & $\begin{array}{l}1217186- \\
1257125\end{array}$ & 49 & Lactob_phig1e_NC_004305 (20) & 41.2 & + & $\begin{array}{l}1217352- \\
1218560\end{array}$ \\
\hline 3 & $27.2 \mathrm{~Kb}$ & Questionable & 70 & $\begin{array}{l}2511806- \\
2539007\end{array}$ & 21 & Lactob_Sha1_NC_019489 (3) & 42.4 & + & $\begin{array}{l}2537850- \\
2539007\end{array}$ \\
\hline 4 & $24.6 \mathrm{~Kb}$ & Incomplete & 30 & $\begin{array}{l}2969719- \\
2994363\end{array}$ & 9 & Entero_IME_EF3_NC_023595 (2) & 45.2 & + & $\begin{array}{l}2981712- \\
2982866\end{array}$ \\
\hline 5 & $17.8 \mathrm{~Kb}$ & Incomplete & 60 & $\begin{array}{l}3002777- \\
3020641\end{array}$ & 11 & Bacill_Waukesha92_NC_025424 (2) & 41.6 & + & $\begin{array}{l}3018894- \\
3019580\end{array}$ \\
\hline 6 & $11.3 \mathrm{~Kb}$ & Questionable & 80 & $\begin{array}{l}3034765- \\
3046067\end{array}$ & 21 & Paenib_PBL1C_NC_048689 (2) & 39.7 & - & - \\
\hline 7 & $5.7 \mathrm{~Kb}$ & Incomplete & 30 & $\begin{array}{l}3136597- \\
3142320\end{array}$ & 9 & $\begin{array}{l}\text { Bacill_vB_BtS_BMBtp14_NC_048640 } \\
(2)\end{array}$ & 38.7 & - & - \\
\hline 8 & $11.7 \mathrm{~Kb}$ & Incomplete & 50 & $\begin{array}{l}3249993- \\
3261724\end{array}$ & 15 & Escher_ESC05_NC_047776 (4) & 38.9 & + & $\begin{array}{l}3261137- \\
3261724\end{array}$ \\
\hline 9 & $29.6 \mathrm{~Kb}$ & Intact & 150 & $\begin{array}{l}3302034- \\
3331708\end{array}$ & 33 & Staphy_SPbeta_like_NC_029119 (4) & 39.3 & + & $\begin{array}{l}3313269- \\
3314018\end{array}$ \\
\hline
\end{tabular}

Horizontal gene transfer between bacteria can usually occur by natural competence or bacteriophage infection (Kleerebezem et al. 2003 ; Liu et al. 2015). The result of sequence homology screening revealed that most of the genes of the DY46 genome were homologous to Lactiplantibacillus plantarum genes and only $1.52 \%$ (49 genes ) of total genes in the genome may have been gained thru horizontal gene transfer from other bacteria, e.g. Pediococcus acidilactici, Pediococcus pentosaceus, Lactiplantibacillus pentosus, Lactiplantibacillus paraplantarum, Leuconostoc sp., Pediococcus damnosus, Paucilactobacillus suebicus, Liquorilactobacillus hordei, Fructilactobacillus lindneri, Lacticaseibacillus paracasei, Loigolactobacillus coryniformis, Lactobacillus kefiranofaciens, Weissella jogaejeotgali, Lactobacillus sanfranciscensis, Lactiplantibacillus argentoratensis, Companilactobacillus paralimentarius, Companilactobacillus sp., Companilactobacillus bobalius, Levilactobacillus brevis, Levilactobacillus fujinensis, Lentilactobacillus buchneri, Lactobacillus crispatus, Levilactobacillus paucivorans, Lactococcus lactis subsp. Iactis bv. diacetylactis, Lactiplantibacillus daowaiensis, Companilactobacillus nodensis, Levilactobacillus lindianensis, Latilactobacillus sakei,

Bifidobacterium longum, Lapidilactobacillus mulanensis, Limosilactobacillus fermentum, Lactobacillus diolivorans. It was determined that most of the vertically transferred genes originated from Lactobacillus species are found in the microbiota of fermented vegetables. Among these 49 genes, 12 transposase genes (PP_02973, PP_02974, PP_02980, PP_02981, PP_03087, PP_03207, PP_03208, PP_03275, PP_03281, PP_03285, PP_03288, PP_03295) which were derived from recombination, repair and replication. Moreover, all the genes considered horizontally transferred were phage related and summarized in Table S13-19.

\section{Probiotic properties}

When new probiotic strains are discovered, certain characterization tests are required to confirm probiotic properties. Therefore, probiotic characterization tests were performed to confirm the probiotic properties of the DY46. The $\beta$-haemolysis test results showed that DY46 does not have $\beta$-hemolytic activity. The cell surface hydrophobicity of DY46 characterized by using xylene. As shown in Fig. 4A, the cell surface hydrophobicity of DY46 appears to increase in direct proportion to the bile salt concentration. Cell surface hydrophobicity of the DY46 was determined as $33 \%, 38.5 \%$ and $46.1 \%$ at 3,5 and $10 \mathrm{~g} / \mathrm{L}$ bile salt concentrations, respectively. The cell surface hydrophobicity of the control sample was found to be at $4.38 \%$. However, similar to present work, it has been reported in previous studies that some lactobacilli, including L. acidophilus and L. johnsonii strains displayed surface hydrophobicity as low as 2-5\% (Rijnaarts et al. 1993; Schillinger et al. 2005). Kaushik et al. (2009) reported that such large differences in cell surface hydrophobicity could occur due to differences in the expression level of cell surface proteins, depending on environmental conditions and/or bacterial strain. 
Auto-aggregation is an important bacterial characteristic in different ecological niches, especially in human and animal mucosa where probiotics confer health benefits. The auto-aggregation capacity is an important factor for maintaining sufficient numbers of probiotic strains under adverse conditions of the oral cavity and gastrointestinal tract. The cellular auto-aggregation test results presented in Fig. 4B revealed that there is an inverse correlation between auto-aggregation and bile salt concentrations. The auto-aggregation ability of DY46 was determined as $85.7 \%$ for the control sample, while it was determined as $84.69 \%, 79.05 \%$ and $51.35 \%$ for bile salt concentrations of 3,5 and $10 \mathrm{~g} / \mathrm{L}$, respectively. (Li et al. 2015 ) reported auto-aggregation ranged from 0.86 to $65.15 \%$ in different $L b$. fermentum strains isolated from various Chinese fermented foods. Ramos et al. (2013) reported an auto-aggregation value between 18.08 to $20.94 \%$ in cocoa originated $L$ b. plantarum strains. Moreover, Goel et al. (2020) reported $52.91 \%$ and $72.84 \%$ auto-aggregation ability for two different $L b$. plantarum strain isolated from Indian fermented foods. Similar to the present study, Aslim et al. (2007) observed a reduction of auto-aggregation capacity in the presence of bile in $L b$. delbrueckii subsp. bulgaricus strains. The fact that the DY46 showed an auto-aggregation capacity of $51.35 \%$ at a bile salt concentration close to the real gastrointestinal tract (GIT) environment is significant to prove its probiotic property. Based on the antimicrobial activity test results, the DY46 displayed an apparent zone of inhibition (> $5 \mathrm{~mm}$ ) against K. pneumoniae (ATCC 13883), P. vulgaris (ATCC 8427) and S. Typhimurium (ATCC 14028) whereas, there is no inhibition zone observed against other test strains. The lack of Pln J peptide in the genome of DY46 strain brings confounding factor of whether inhibiton zones achieved against test pathogens might also be due to the ogranic acids produced by DY46.

It is necessary to test probiotic candidates against acid and bile salts to determine their resistance under inevitable conditions of the human gastrointestinal tract (GIT) (Angmo et al. 2016). The growth kinetics of DY46 at different $\mathrm{pH}(2,3,4,5$ and 7$)$ conditions at 30 and $37^{\circ} \mathrm{C}$ are shown in Figures S2 and S3. No or ignorable level of growths seen at $\mathrm{pH}=2$ and $\mathrm{pH}=3$ conditions for both 30 and 37C. Similar findings were also reported that cell density of Lactobacilli are significantly influenced by low pH, especially at 1.5 and 2 (Guo et al. 2010; Ortakci and Sert 2012; Ortakci et al. 2012; Angmo et al. 2016)

The duration of lag phase achieved was $\mathrm{pH}=7<\mathrm{pH}=5<\mathrm{pH}=4$ in both 30 and $37^{\circ} \mathrm{C}$. The maximum specific growth rates achieved at both temperatures were as follows $\mathrm{pH}=7>\mathrm{pH}=5>\mathrm{pH}=4$. Similarly, final cell turbidities achieved were $\mathrm{pH}=7>\mathrm{pH}=5>\mathrm{pH}=4$. The $\mu_{\mathrm{max}}$ levels achieved at 30 and $37^{\circ} \mathrm{C}$ were slightly different with the latter providing better growth performance. This perhaps relates to the probiotic potential of DY46 that can proliferate at a body temperature of $37^{\circ} \mathrm{C}$. The decreasing $\mu_{\max }$ values and poor or no growth seen at lower pH values are perhaps due to the cellular machinery effort to maintain relatively neutral $\mathrm{pH}$ values in the cytoplasm at the expenditure of ATP to push thru $\mathrm{H}^{+}$cations across the outside of the membrane (Axelsson 2004).

The growth kinetics of DY46 at different bile $\left(0.3,0.5,1 \%\right.$ and control) conditions at 30 and $37^{\circ} \mathrm{C}$ are shown in Figures S4 and S5. A significantly lower lag phase duration observed at $37^{\circ} \mathrm{C}$ vs $30^{\circ} \mathrm{C}$. The $\mu_{\max }$ values achieved at $37^{\circ} \mathrm{C}$ were as follows Control (No bile) $>0.3 \%$ bile $>0.5 \%$ bile $>1 \%$ bile. Final cell densities achieved at $37^{\circ} \mathrm{C}$ were Control (No bile) $>0.3 \%$ bile $>0.5 \%$ bile $=1 \%$ bile. We speculate that the bile salt exerts certain stress on the cell and is triggered by temperature. Nevertheless, DY46 can still proliferate to remarkable cell concentrations as measured with microplate reader across all bile levels even at $37^{\circ} \mathrm{C}$. It was interesting to note that although longer lag phases achieved for all bile treatments at $30^{\circ} \mathrm{C}$, the cells further caught up with higher $\mu_{\max }$ values achieved compared to $37^{\circ} \mathrm{C}$. This shows $\mathrm{DY} 46$ perhaps could better tolerate bile salt stress at a lower temperature which can be supported by the observation of similar final cell densities across all bile concentrations at $30^{\circ} \mathrm{C}$.

Overall, better growth kinetics achieved at $37^{\circ} \mathrm{C}$ for $\mathrm{pH}$ conditions tested though lower $\mathrm{pH}$ values reduced or decreased growth completely. Although a shorter lag phase seen at $37^{\circ} \mathrm{C}$ with all bile concentrations evaluated, DY 46 cells better-tolerated bile salt at $30^{\circ} \mathrm{C}$ with higher $\mu_{\text {max }}$ and final cell concentrations obtained. The DY46 can be resisting and proliferating under adverse conditions with moderately lower pH values and bile concentration mimicking the human GIT.

In conclusion, whole-genome sequencing and physiological characterization of $L$ b. plantarum DY46 isolated from Shalgam has been performed to determine probiotic properties of this novel strain. Genome analysis revealed this strain follows a facultative heterofermentative sugar metabolism where hexoses are cleaved thru glycolysis versus pentoses are hydrolyzed via the pentose phosphate pathway. Genome evidence predicted DY46 could biosynthesize Plantaricin-E, Plantaricin-F, Plantaricin-K showing the antimicrobial potential of DY46 which was confirmed by in vitro antagonistic activity test that supernatants of DY46 culture provided inhibition zones against K. pneumonia ATCC 13883, P. vulgaris ATCC 8427, S. Thypimirium ATCC 14028. Also, DY46 is tolerant to acid and bile concentrations mimicking human gastrointestinal conditions. Overall, $L b$. plantarum DY46 is a promising bacterium possessing certain probiotic traits confirmed by in vitro analysis and perhaps a potential dietary supplement candidate that might provide therapeutic benefits to the host.

\section{Declarations}

\section{Acknowledgement}

This study has been financially supported by Erciyes University Scientific Research Projects Coordination Unit under grant number FKB-2020-10551.

\section{References}


1. Abriouel H, Casado Muñoz M, del C, Lavilla Lerma L, et al (2015) New insights in antibiotic resistance of Lactobacillus species from fermented foods. Food Res Int 78:465-481. https://doi.org/10.1016/j.foodres.2015.09.016

2. Agirman B, Settanni L, Erten H (2021) Effect of different mineral salt mixtures and dough extraction procedure on the physical, chemical and microbiological composition of Şalgam: A black carrot fermented beverage. Food Chem 344:128618.

https://doi.org/10.1016/j.foodchem.2020.128618

3. Alcock BP, Raphenya AR, Lau TTY et al (2020) CARD 2020: Antibiotic resistome surveillance with the comprehensive antibiotic resistance database. Nucleic Acids Res 48:D517-D525. https://doi.org/10.1093/nar/gkz935

4. Álvarez-Cisneros YM, Ponce-Alquicira E (2018) Antibiotic Resistance in Lactic Acid Bacteria Chapter. Intech0pen 1-15. https://doi.org/10.5772/intechopen.80624

5. Angmo K, Kumari A, Savitri, Bhalla TC (2016) Probiotic characterization of lactic acid bacteria isolated from fermented foods and beverage of Ladakh. LWT - Food Science Technology 66:428-435. https://doi.org/10.1016/j.Iwt.2015.10.057

6. Aramaki T, Blanc-Mathieu R, Endo H et al (2020) KofamKOALA: KEGG Ortholog assignment based on profile HMM and adaptive score threshold. Bioinformatics 36:2251-2252. https://doi.org/10.1093/bioinformatics/btz859

7. Arndt D, Grant JR, Marcu A et al (2016) PHASTER: a better, faster version of the PHAST phage search tool. Nucleic acids research 44:W16-W21. https://doi.org/10.1093/nar/gkw387

8. Aslim B, Onal D, Beyatli Y (2007) Factors influencing autoaggregation and aggregation of Lactobacillus delbrueckii subsp. bulgaricus isolated from handmade yogurt. J Food Prot 70:223-227. https://doi.org/10.4315/0362-028X-70.1.223

9. Axelsson L (2004) Lactic Acid Bacteria: Classification and Physiology. In: Salminen S, von Wright A, Ouweahnd A (eds) Lactic Acid Bacteria: Microbiological and Functional Aspects, Third Edition, Third Edit. Marcel Dekker, Inc., New York, pp 1-66

10. Bortolaia V, Kaas RS, Ruppe E et al (2020) ResFinder 4.0 for predictions of phenotypes from genotypes. J Antimicrob Chemother 75:34913500. https://doi.org/10.1093/jac/dkaa345

11. Buron-Moles G, Chailyan A, Dolejs I et al (2019) Uncovering carbohydrate metabolism through a genotype-phenotype association study of 56 lactic acid bacteria genomes. Appl Microbiol Biotechnol 103:3135-3152. https://doi.org/10.1007/s00253-019-09701-6

12. Campedelli I, Mathur H, Salvetti E et al (2019) Genus-wide assessment of antibiotic resistance in Lactobacillus spp. Appl Environ Microbiol 85:1-21. https://doi.org/10.1128/AEM.01738-18

13. CLSI M100-S22 (2012) Performance Standards for Antimicrobial Susceptibility Testing. Twenty-Second Informational Supplement

14. Davis JJ, Wattam AR, Aziz RK et al (2020) The PATRIC Bioinformatics Resource Center: Expanding data and analysis capabilities. Nucleic Acids Res 48:D606-D612. https://doi.org/10.1093/nar/gkz943

15. Diep et al (2009) An overview of the mosaic bacteriocin pln loci from Lactobacillus plantarum. Peptides 30:1562-1574

16. Eiteman MA, Ramalingam S (2015) Microbial production of lactic acid. Biotech Lett 37:955-972. https://doi.org/10.1007/s10529-015-1769-5

17. Ekinci FY, Baser GM, Özcan E et al (2016) Characterization of chemical, biological, and antiproliferative properties of fermented black carrot juice, shalgam. Eur Food Res Technol 242:1355-1368. https://doi.org/10.1007/s00217-016-2639-7

18. Evanovich E, De Souza Mendonça Mattos PJ, Guerreiro JF (2019) Comparative genomic analysis of lactobacillus plantarum: An overview. International Journal of Genomics 2019:. https://doi.org/10.1155/2019/4973214

19. Ferain T, Garmyn D, Bernard N et al (1994) Lactobacillus plantarum IdhL gene: Overexpression and deletion. J Bacteriol 176:596-601. https://doi.org/10.1128/jb.176.3.596-601.1994

20. Flórez AB, Mayo B (2018) Genome analysis of Lactobacillus plantarum LL441 and genetic characterisation of the locus for the lantibiotic plantaricin C. Front Microbiol 9:1-11. https://doi.org/10.3389/fmicb.2018.01916

21. Gaggia F, Di Gioia D, Baffoni L, Biavati B (2011) The role of protective and probiotic cultures in food and feed and their impact in food safety. Trends in Food Science Technology 22:S58-S66. https://doi.org/10.1016/j.tifs.2011.03.003

22. Gänzle MG, Follador R (2012) Metabolism of oligosaccharides and starch in lactobacilli: A review. Front Microbiol 3:1-15. https://doi.org/10.3389/fmicb.2012.00340

23. Gao Y, Liu Y, Sun M et al (2020) Physiological function analysis of Lactobacillus plantarum Y44 based on genotypic and phenotypic characteristics. J Dairy Sci 103:5916-5930. https://doi.org/10.3168/jds.2019-18047

24. Gaudana SB, Dhanani AS, Bagchi T (2010) Probiotic attributes of lactobacillus strains isolated from food and of human origin. Br J Nutr 103:1620-1628. https://doi.org/10.1017/S0007114509993643

25. Goel A, Halami PM, Tamang JP (2020) Genome Analysis of Lactobacillus plantarum Isolated From Some Indian Fermented Foods for Bacteriocin Production and Probiotic Marker Genes. Front Microbiol 11:1-12. https://doi.org/10.3389/fmicb.2020.00040

26. Gonzalez B, Arca P, Mayo B, Suarez JE (1994) Detection, purification, and partial characterization of plantaricin C, a bacteriocin produced by a Lactobacillus plantarum strain of dairy origin. Appl Environ Microbiol 60:2158-2163. https://doi.org/10.1128/aem.60.6.2158-2163.1994

27. Gueimonde M, Sánchez B, de los Reyes-Gavilán CG, Margolles A (2013) Antibiotic resistance in probiotic bacteria. Front Microbiol 4:1-6. https://doi.org/10.3389/fmicb.2013.00202

Page 9/14 
28. Guo XH, Kim JM, Nam HM et al (2010) Screening lactic acid bacteria from swine origins for multistrain probiotics based on in vitro functional properties. Anaerobe 16:321-326. https://doi.org/10.1016/j.anaerobe.2010.03.006

29. Havarstein LS, Diep DB, Nes IF (1995) A family of bacteriocin ABC transporters carry out proteolytic processing of their substrates concomitant with export. Mol Microbiol 16:229-240. https://doi.org/10.1111/j.1365-2958.1995.tb02295.x

30. Heel AJ, Van JA, De, Montalba M et al (2013) BAGEL3: automated identification of genes encoding bacteriocins and (non-) bactericidal posttranslationally modified peptides. 41:448-453. https://doi.org/10.1093/nar/gkt391

31. Inglin RC, Meile L (2020) Complete and Assembled Genome Sequence of Lactobacillus plantarum RI-113 Isolated from Salami. Genome Announcements 5:e00183-e00117. https://doi.org/https://doi.org/10.1128/ genomeA.00183 - 17

32. Jia FF, Zhang LJ, Pang XH et al (2017) Complete genome sequence of bacteriocin-producing Lactobacillus plantarum KLDS1.0391, a probiotic strain with gastrointestinal tract resistance and adhesion to the intestinal epithelial cells. Genomics 109:432-437. https://doi.org/10.1016/j.ygeno.2017.06.008

33. Jiang J, Shi B, Zhu D et al (2012) Characterization of a novel bacteriocin produced by Lactobacillus sakei LSJ618 isolated from traditional Chinese fermented radish. Food Control 23:338-344. https://doi.org/10.1016/j.foodcont.2011.07.027

34. Juhas M, Van Der Meer JR, Gaillard M et al (2009) Genomic islands: Tools of bacterial horizontal gene transfer and evolution. FEMS Microbiol Rev 33:376-393. https://doi.org/10.1111/j.1574-6976.2008.00136.x

35. Kanehisa M, Sato Y, Morishima K (2016) BlastKOALA and GhostKOALA: KEGG Tools for Functional Characterization of Genome and Metagenome Sequences. J Mol Biol 428:726-731. https://doi.org/10.1016/j.jmb.2015.11.006

36. Kaushik JK, Kumar A, Duary RK et al (2009) Functional and probiotic attributes of an indigenous isolate of lactobacillus plantarum. PLoS ONE 4:. https://doi.org/10.1371/journal.pone.0008099

37. Klarin B, Larsson A, Molin G, Jeppsson B (2019) Susceptibility to antibiotics in isolates of Lactobacillus plantarum RAPD-type Lp299v, harvested from antibiotic treated, critically ill patients after administration of probiotics. Microbiology0pen 8:1-9.

https://doi.org/10.1002/mbo3.642

38. Kleerebezem M, Boekhorst J, Van Kranenburg R et al (2003) Complete genome sequence of Lactobacillus plantarum WCFS1. Proc Natl Acad Sci USA 100:1990-1995. https://doi.org/10.1073/pnas.0337704100

39. Lee I, Kim YO, Park SC, Chun J (2016) OrthoANI: An improved algorithm and software for calculating average nucleotide identity. Int J Syst Evol Microbiol 66:1100-1103. https://doi.org/10.1099/ijsem.0.000760

40. Li P, Li X, Gu Q et al (2016) Comparative genomic analysis of Lactobacillus plantarum ZJ316 reveals its genetic adaptation and potential probiotic profiles. Journal of Zhejiang University: Science B 17:569-579. https://doi.org/10.1631/jzus.B1600176

41. Li Q, Liu X, Dong M et al (2015) Aggregation and adhesion abilities of 18 lactic acid bacteria strains isolated from traditional fermented food. International Journal of Agricultural Policy Research 3:84-92

42. Liu CJ, Wang R, Gong FM et al (2015) Complete genome sequences and comparative genome analysis of Lactobacillus plantarum strain 5 - 2 isolated from fermented soybean. Genomics 106:404-411. https://doi.org/10.1016/j.ygeno.2015.07.007

43. McMahon DJ, Bowen IB, Green I et al (2020) Growth and survival characteristics of Paucilactobacillus wasatchensis WDC04. J Dairy Sci 103:8771-8781. https://doi.org/10.3168/jds.2020-18597

44. Mishra V, Prasad DN (2005) Application of in vitro methods for selection of Lactobacillus casei strains as potential probiotics. Int J Food Microbiol 103:109-115. https://doi.org/10.1016/j.ijfoodmicro.2004.10.047

45. Mokoena MP (2017) Lactic acid bacteria and their bacteriocins: Classification, biosynthesis and applications against uropathogens: A minireview. Molecules 22:. https://doi.org/10.3390/molecules22081255

46. Nes IF, Diep DB, Håvarstein LS et al (1996) Biosynthesis of bacteriocins in lactic acid bacteria. Antonie van Leeuwenhoek. International Journal of General Molecular Microbiology 70:113-128. https://doi.org/10.1007/BF00395929

47. Ni K, Wang Y, Li D et al (2015) Characterization, Identification and Application of Lactic Acid Bacteria Isolated from Forage Paddy Rice Silage. PLoS ONE 1-14. https://doi.org/10.1371/journal.pone.0121967

48. Orita HM, Oh HT, Ukuda SF et al (2008) Comparative Genome Analysis of Lactobacillus reuteri and Lactobacillus fermentum Reveal a Genomic Island for Reuterin and Cobalamin Production. 151-161

49. Ortakci F, Broadbent JR, McManus WR, McMahon DJ (2012) Survival of microencapsulated probiotic Lactobacillus paracasei LBC-1e during manufacture of Mozzarella cheese and simulated gastric digestion. J Dairy Sci 95:6274-6281. https://doi.org/10.3168/jds.2012-5476

50. Ortakci F, Sert S (2012) Stability of free and encapsulated Lactobacillus acidophilus ATCC 4356 in yogurt and in an artificial human gastric digestion system. J Dairy Sci 95:6918-6925. https://doi.org/10.3168/jds.2012-5710

51. Papagianni M (2012) Metabolic engineering of lactic acid bacteria for the production of industrially important compounds Abstract: Lactic acid bacteria $(\mathrm{LAB})$ are receiving increased attention for use as cell factories for the production of metabolites with wide use by the. Computational and Structural Biotechnology Journal 1-8 
52. Parente E, Ciocia F, Ricciardi A et al (2010) Diversity of stress tolerance in Lactobacillus plantarum, Lactobacillus pentosus and Lactobacillus paraplantarum: A multivariate screening study. Int J Food Microbiol 144:270-279. https://doi.org/10.1016/j.ijfoodmicro.2010.10.005

53. Pei Z, Sadiq FA, Han X et al (2020) Identification, characterization, and phylogenetic analysis of eight new inducible prophages in Lactobacillus. Virus Res 286:198003. https://doi.org/10.1016/j.virusres.2020.198003

54. Ramos CL, Thorsen L, Schwan RF, Jespersen L (2013) Strain-specific probiotics properties of Lactobacillus fermentum, Lactobacillus plantarum and Lactobacillus brevis isolates from Brazilian food products. Food Microbiol 36:22-29. https://doi.org/10.1016/j.fm.2013.03.010

55. Ribeiro SC, Stanton C, Yang B et al (2018) Conjugated linoleic acid production and probiotic assessment of Lactobacillus plantarum isolated from Pico cheese. LWT - Food Science Technology 90:403-411. https://doi.org/10.1016/j.lwt.2017.12.065

56. Rijnaarts HHM, Norde W, Bouwer EJ et al (1993) Bacterial adhesion under static and dynamic conditions. Appl Environ Microbiol 59:32553265. https://doi.org/10.1128/aem.59.10.3255-3265.1993

57. Schillinger U, Guigas C, Holzapfel WH (2005) In vitro adherence and other properties of lactobacilli used in probiotic yoghurt-like products. Int Dairy J 15:1289-1297. https://doi.org/10.1016/j.idairyj.2004.12.008

58. Seddik HA, Bendali F, Gancel F et al (2017) Lactobacillus plantarum and Its Probiotic and Food Potentialities. Probiotics Antimicrobial Proteins 9:111-122. https://doi.org/10.1007/s12602-017-9264-z

59. Sharma C, Gulati S, Thakur N, Pal B (2017) Antibiotic sensitivity pattern of indigenous lactobacilli isolated from curd and human milk samples. 3 Biotech 7:1-14. https://doi.org/10.1007/s13205-017-0682-0

60. Sharma P, Tomar SK, Sangwan V et al (2016) Antibiotic Resistance of Lactobacillus sp. Isolated from Commercial Probiotic Preparations. J Food Saf 36:38-51. https://doi.org/10.1111/jfs.12211

61. Siezen RJ, Tzeneva VA, Castioni A et al (2010) Phenotypic and genomic diversity of Lactobacillus plantarum strains isolated from various environmental niches. Environ Microbiol 12:758-773. https://doi.org/10.1111/j.1462-2920.2009.02119.x

62. Stiles ME, Holzapfel WH (1997) Lactic acid bacteria of foods and their current taxonomy. Int J Food Microbiol 36:1-29. https://doi.org/10.1016/S0168-1605(96)01233-0

63. Stothard P, Wishart DS (2005) Circular genome visualization and exploration using CGView. 21:537-539. https://doi.org/10.1093/bioinformatics/bti054

64. Tai HF, Foo HL, Rahim RA et al (2015) Molecular characterisation of new organisation of plnEF and plw loci of bacteriocin genes harbour concomitantly in Lactobacillus plantarum I-UL4. Microbial Cell Factories 14:. https://doi.org/10.1186/s12934-015-0280-y

65. Tamang JP, Shin DH, Jung SJ, Chae SW (2016) Functional properties of microorganisms in fermented foods. Front Microbiol 7:1-13. https://doi.org/10.3389/fmicb.2016.00578

66. Tamang JP, Tamang B, Schillinger U et al (2009) Functional properties of lactic acid bacteria isolated from ethnic fermented vegetables of the Himalayas. Int J Food Microbiol 135:28-33. https://doi.org/10.1016/j.ijfoodmicro.2009.07.016

67. Tanguler H, Cankaya A, Agcam E, Uslu H (2021) Effect of temperature and production method on some quality parameters of fermented carrot juice (Shalgam). Food Bioscience 41:100973. https://doi.org/10.1016/j.fbio.2021.100973

68. Tanguler H, Erten H (2012) Occurrence and growth of lactic acid bacteria species during the fermentation of shalgam (salgam), a traditional Turkish fermented beverage. LWT - Food Science Technology 46:36-41. https://doi.org/10.1016/j.Iwt.2011.10.026

69. Tatusova T, Dicuccio M, Badretdin A et al (2016) NCBI prokaryotic genome annotation pipeline. Nucleic Acids Res 44:6614-6624. https://doi.org/10.1093/nar/gkw569

70. Todorov SD (2009) Bacteriocins from Lactobacillus plantarum production, genetic organization and mode of action. Brazilian Journal of Microbiology 40:209-221. https://doi.org/10.1590/s1517-83822009000200001

71. Ventura M, Canchaya C, Kleerebezem M et al (2003) The prophage sequences of Lactobacillus plantarum strain WCFS1. 316:245-255. https://doi.org/10.1016/j.virol.2003.08.019

72. Wang Y, Chen C, Ai L et al (2011) Complete genome sequence of the probiotic Lactobacillus plantarum ST-III. J Bacteriol 193:313-314. https://doi.org/10.1128/JB.01159-10

73. Wouters D, Grosu-Tudor S, Zamfir M, De Vuyst L (2013) Bacterial community dynamics, lactic acid bacteria species diversity and metabolite kinetics of traditional Romanian vegetable fermentations. J Sci Food Agric 93:749-760. https://doi.org/10.1002/jsfa.5788

74. Yu X, Li Y, Wu Q et al (2020) Genomic Analysis for Antioxidant Property of Lactobacillus plantarum FLPL05 from Chinese Longevity People. Probiotics Antimicrobial Proteins 12:1451-1458. https://doi.org/10.1007/s12602-020-09704-0

75. Zhang W, Ji H, Zhang D et al (2018) Complete Genome Sequencing of Lactobacillus plantarum ZLP001, a Potential Probiotic That Enhances Intestinal Epithelial Barrier Function and Defense Against Pathogens in Pigs. Front Physiol 9:1-7. https://doi.org/10.3389/fphys.2018.01689

76. Zhang ZY, Liu C, Zhu YZ et al (2012) Safety assessment of Lactobacillus plantarum JDM1 based on the complete genome. Int J Food Microbiol 153:166-170. https://doi.org/10.1016/j.ijfoodmicro.2011.11.003

77. Zheng J, Ruan L, Sun M (2015) A Genomic View of Lactobacilli and Pediococci Demonstrates that Phylogeny Matches Ecology and Physiology. 81:7233-7243. https://doi.org/10.1128/AEM.02116-15

Page 11/14 
78. Zheng M, Zhang R, Tian X et al (2017) Assessing the risk of probiotic dietary supplements in the context of antibiotic resistance. Front Microbiol 8:1-8. https://doi.org/10.3389/fmicb.2017.00908

\section{Figures}

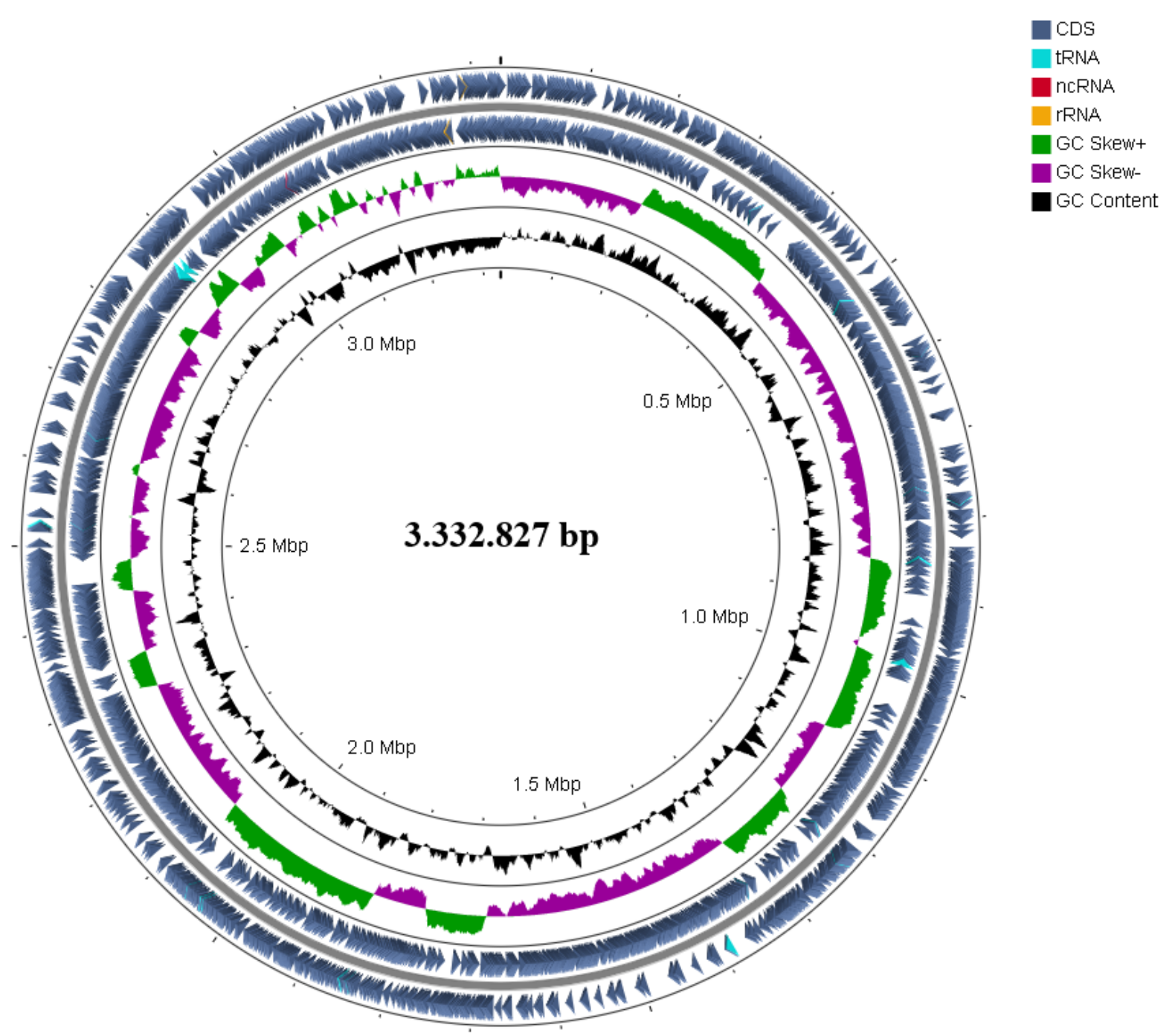

Figure 1

The genome atlas of Lactiplantibacillus plantarum DY46. The 1st and 2nd outer circles illustrate prognosticated protein coding sequences, tRNA, ncRNA, rRNA on the forward and reverse strands, respectively. In the third circle depicts the GC skew $(\mathrm{G}-\mathrm{C}) /(\mathrm{G}+\mathrm{C})$. The fourth circle display the GC content of the genome. The last circle shows the genome size. 


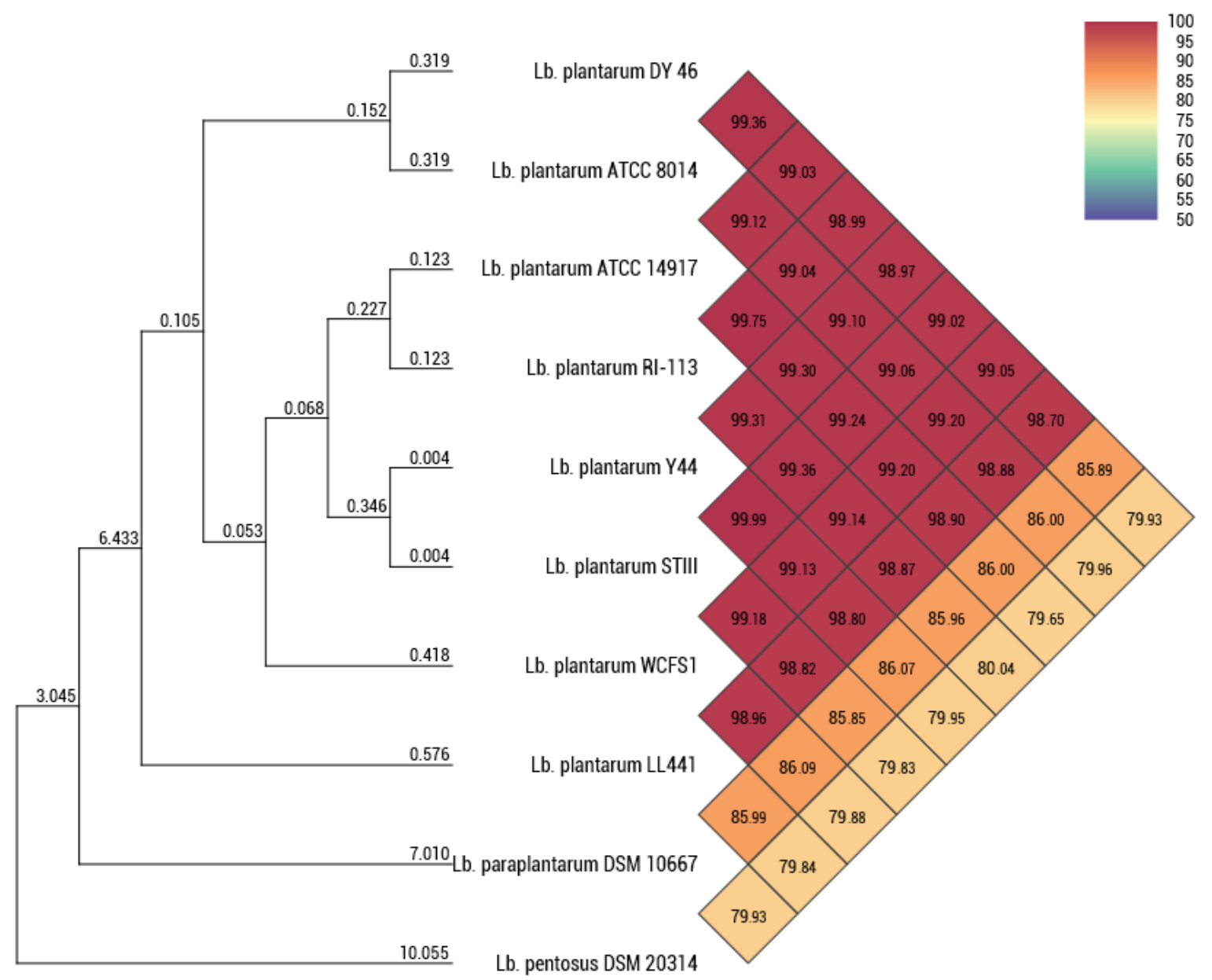

Figure 2

Orthologous Average Nucleotide Identity (Ortho ANI) values of Lactiplantibacillus plantarum DY46 and other compared Lactiplantibacillus species.

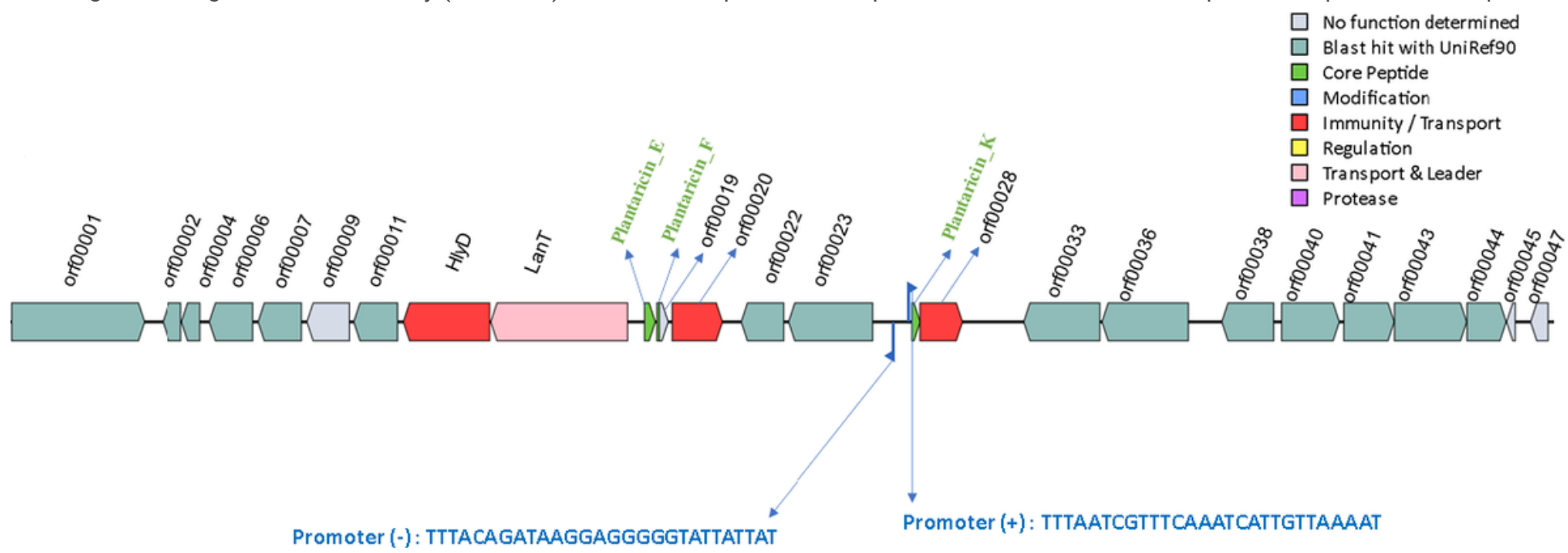

\section{Figure 3}

The predicted gene cluster responsible from the biosynthesis of Plantaricins by using BAGEL4 webserver. 

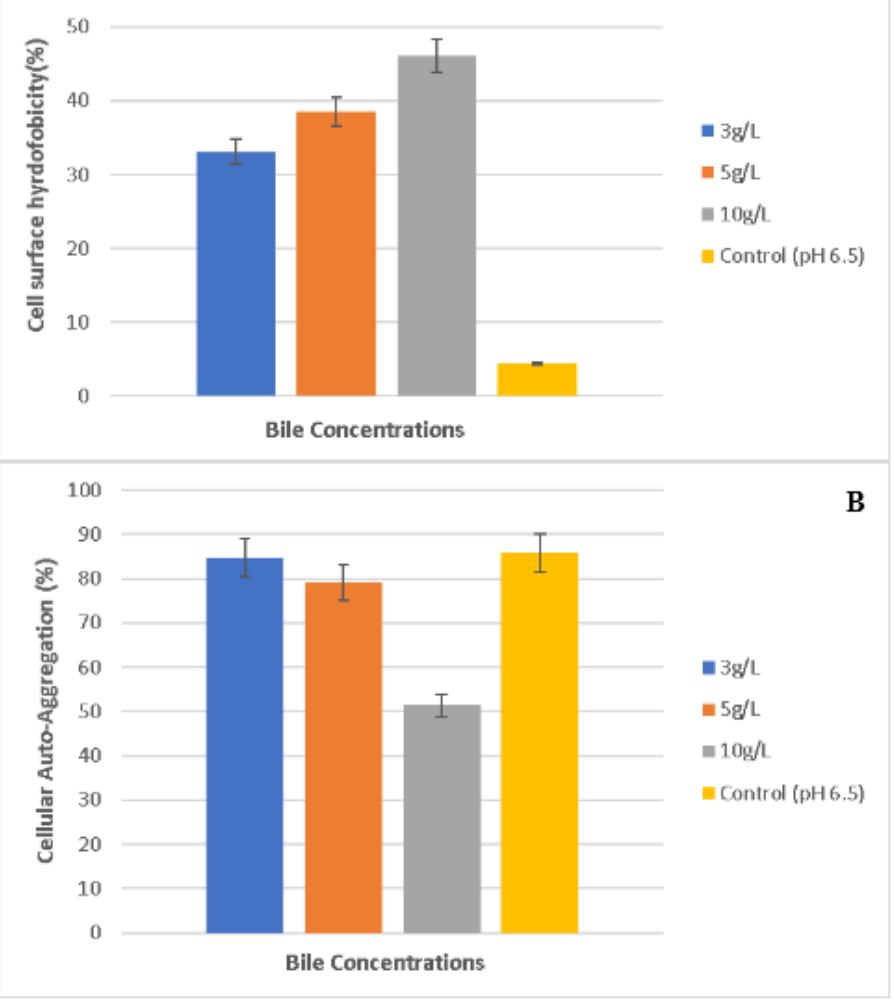

Figure 4

Graphical presentation of cell surface hydrofobicity (A) and cellular auto-aggregation (B) test results

\section{Supplementary Files}

This is a list of supplementary files associated with this preprint. Click to download.

- SUPPLEMENTARYMATERIALSDY46.pdf 